\title{
El desplazamiento en Colombia y sus diversas miradas
}

\author{
Lizandro Alfonso Cabrera-Suarez ${ }^{*}$
}

\footnotetext{
Magíster en Derecho, Universidad Sergio Arboleda. Abogado, Universidad Santiago de Cali. Investigador junior, Colciencias. Docente posgrados Universidad de la Amazonía.

Correo electrónico:

llzandrocabrera@hotmail.com
}

Recibido: 12 de septiembre del 2016

Aprobado: 26 de octubre del 2016

Cómo citar este artículo: Lizandro Cabrera Suárez. El desplazamiento en Colombia y sus diversas miradas. DIxI 25. Enero 2017. Págs. 25-40. doi: http://dx.doi.org/10.16925/ di.v19i25.1818

\section{Resumen}

Tema y alcance: los desplazados día a día se ven acompañados por el desprecio y la humillación. El efecto que esto produce tal vez no es apreciable para el habitante de Cali, quien, por el contrario, los ve como un problema y una carga social. Sin embargo, su calidad de vida se opone con el altísimo negocio de los que ahora ocupan sus tierras. Características: los desplazados se ven obligados a mimetizarse en la sociedad y olvidar la producción en el campo, a cambiar su vida y aprender a ganar su sustento. Las sociedades mutan y la de Colombia más por ser un país en guerra. Hallazgos: la realidad social que vive el desplazado en Cali y los posibles mecanismos de orientación frente a la actitud y ayuda que se le puede prestar a estos colombianos que, por fuerzas externas, se ven obligados a tocar puertas con la esperanza de encontrarle solución definitiva a su problema. Además, ampliará la visión del colombiano frente al desplazado para que no sea más un problema que se nombra en los noticieros, pero que una vez en la calle es invisible para el ciudadano. El Estado debe prepararse para afrontar los nuevos retos que le propone la sociedad, y el desplazamiento es uno de ellos. Conclusiones: los desplazados son más noticia al huir que al morir.

Palabras clave: conflicto armado, desplazados, Estado social de derecho, posconflicto. 


\title{
Displacement in Colombia and its various views
}

\begin{abstract}
Theme and scope: from day to day the displaced are accompanied by contempt and humiliation. The effect it has is perhaps not appreciated by the inhabitant of Cali, who, on the contrary, sees them as a problem and a social burden. However, their quality of life is opposed to the profitable business of those who now occupy their lands. Characteristics: the displaced are forced to camouflage themselves in society and leave behind production in the countryside, change their lives and learn to earn their living. Societies transform, especially in Colombia for being a country at war. Findings: the social reality that the displaced live in Cali and the possible mechanisms for guiding the attitude and help that can be provided to these Colombians who, due to external circumstances, are forced to knock on doors in the hope of finding a final solution to their problem. In addition, it will expand the view of the Colombian vis-a-vis the displaced so that it is no longer a problem that is mentioned in the news, but that once on the street is invisible to the citizen. The State must prepare itself to face the new challenges posed by society, displacement being one of them. Conclusions: the displaced are paid more attention when they flee than when they die.
\end{abstract}

Keywords: armed conflict, the displaced, human rights, rule of law, post-conflict.

\section{O deslocamento na Colômbia e seus diversos olhares}

\section{Resumo}

Tema e alcance: os deslocados dia a dia se veem acompanhados pelo desprezo e pela humilhação. O efeito que isso produz talvez não seja perceptível para o habitante de Cali, que, pelo contrário, os vê como um problema e uma carga social. Contudo, sua qualidade de vida se opõe com o altíssimo negócio dos que agora ocupam suas terras. Características: os deslocados se veem obrigados a se mimetizar na sociedade e a esquecer a produção no campo, a mudar sua vida e a aprender a ganhar seu sustento. As sociedades se transformam e a da Colômbia ainda mais por ser um país em guerra. Achados: a realidade social que o deslocado vive em Cali e os possíveis mecanismos de orientação diante da atitude e da ajuda prestada a esses colombianos que, por forças externas, são obrigados a bater de porta em porta com a esperança de encontrar solução definitiva a seu problema. Além disso, ampliará a visão do colombiano sobre o deslocado para que este não seja mais um problema que aparece só nos noticiários, mas que se torna invisível quando está na rua. O Estado deve se preparar para enfrentar os novos desafios que a sociedade apresenta, e o deslocamento é um deles. Conclusões: os deslocados são mais notícia ao fugirem do que ao morrerem.

Palavras-chave: conflito armado, deslocados, Estado social de direito, pós-conflito. 


\section{INTRODUCCIÓN}

Desde que nacen los colombianos están sometidos a diario en el ámbito familiar, escolar, social, político y religioso, entre otros, a los más grandes atropellos, en los que se les vulneran los derechos mínimos. Esto culturalmente parece que fuera normal, y por eso tal vez muchos, a falta de no haber contado con espacios como lo define claramente la Constitución, deciden arremeter contra la sociedad en busca de un reconocimiento; no solo al tomar las armas e internándose en el monte, sino imperando en nuestros contextos culturales con "la voz del más fuerte", la ley del silencio, amenazas, destruyendo la naturaleza, o desalojando a las personas de sus tierras. Santiago de Cali, con un poco más de 2000000 de habitantes, no ha sido ajena a esta situación, de manera que se presenta actualmente ante el mundo - desde la visión de los sectores sociales-, como una ciudad insegura con altos índices de violencia, segmentada social y culturalmente, un municipio en la quiebra con un número muy alto de desempleo (19,6\%), y una imagen deteriorada a nivel nacional e internacional, además de ser considerada "la ciudad de los desplazados". Ante este fenómeno, el gobierno vallecaucano ha buscado innumerables soluciones a partir de la creación de instituciones y entidades que ayuden a minimizar esta situación, y sobre todo que se encarguen de ayudar a estas personas a adaptarse en la zona urbana o a reinsertarlas en su antiguo medio. Sin embargo, no se han obtenido óptimos resultados, ya que solo se ha logrado es aumentar los índices de violencia, desempleo y marginalidad, así como la creación de leyes poco coercitivas, entre otros factores.

Los desplazados son personas que han sufrido mucho. Por un lado, por haber sido desalojadas violentamente de su medio, y por otro, al tener que llegar a un lugar que es totalmente diferente al suyo y verse rodeados de personas con costumbres distintas, y que a la vez se muestran indiferentes ante ellos y ante esta grave situación. Vivimos un momento histórico en el que sabemos mucho, pero comprendemos muy poco, y estas personas necesitan ser comprendidas más que ser conocidas. Solo podemos entender aquello de lo que somos capaces de formar parte, aquello con lo cual somos capaces de integrarnos y, sobre todo, aquello que somos capaces de penetrar profundamente. Por esta razón, se busca en este proyecto de investigación la reconstrucción del imaginario colectivo frente a los desplazados en Santiago de Cali.

La concentración de tierras nace en la etapa colonial (siglo xv) en manos determinadas, así como la esclavitud y el desalojo de aborígenes de sus tierras, la inquisición y las políticas administrativas arcaicas. Así empezó la destrucción del país (expropiando al nativo para desplazarlo a la sobrevivencia), por luchas de poder y el poder de tierras. De ahí fueron surgiendo la Guerra de los Mil Días, la masacre de las Bananeras, el conflicto armado de guerrillas, la lucha contra narcotraficantes (la de estos por cultivar amapola), las pandillas urbanas, el modelo neoliberal acogido arbitrariamente a favor de la clase dominante, etc. El origen del desplazamiento fue inmediato a acciones políticas y administrativas injustas y desequilibradas, es decir, la intolerancia, el odio y la violación de los Derechos Humanos no dan espera al nativo, al campesino o a la persona urbana.

De acuerdo con la Comisión de Derechos Humanos de la Conferencia Episcopal Nacional, en 1998, los desplazados llegaban a 1100 000, en 1999 a 1500 000, y en el 2004 a 2500 000. Estos actores pasivos son, en su mayoría, campesinos que durante los 10 años huyeron de las amenazas y de los homicidios de los grupos guerrilleros, de atropellos cometidos por paramilitares, de abusos y ejecuciones extrajudiciales de la fuerza pública y de la violencia generalizada provocada por el narcotráfico.

Un componente importante de la violencia que ha sufrido el país ha sido fruto de las masacres, entendiendo por este término "la muerte violenta, indiscriminada y arbitraria en una misma acción criminal, de tres o más personas, que generalmente hacen parte de la sociedad civil o más específicamente, de grupos vulnerables de la sociedad". ${ }^{1}$ Sin embargo, otro tipo de acciones tales como amenazas directas o indirectas, asesinatos, atentados, torturas, desapariciones o ataques aéreos, o incluso el miedo a la violencia vivido por los individuos en su lugar de origen, motivan el desplazamiento y tienen igual un impacto social, psicológico y económico en la población.

"El desplazamiento forzado ha afectado a Colombia en los últimos 15 años. Se disponen en la actualidad de suficientes estudios con la profundidad y validez epistemológicas necesarias, como para entender y describir la problemática de la población desplazada y, a partir de esto, proponer programas de intervención pública que mitiguen, en parte, los

\footnotetext{
1. Cf. Diana Carolina Cáceres Matías, Vilma Fabiola Izquierdo, Leonardo Mantilla, Marta Patricia Velandia, Angela González Puche y Jorge Jara Consuegra. Perfil EPIDEMiológico de LA Población Desplaza en Barrio Mandela. Ministerio de Salud, Instituto Nacional de Salud. (2001). Disponible en http://www.disaster-info. net/desplazados/informes/mandela/informemandela.pdf
} 
efectos deletéreos ocasionados por este fenómeno en la población afectada.

Las áreas de conflicto en 1990 no estaban bien establecidas; las grandes y medianas ciudades ofrecían más seguridad que el área rural, razón por la cual la población desplazada migró hacia esos sitios, pero no existía un plan de contingencia que respondiera a las demandas crecientes y a las migraciones generadas por el fenómeno de desplazamiento. Desde 1995, se mantiene una tendencia anual ascendente en el número de personas desplazadas en Colombia. Para el 2004, se estima que el fenómeno de desplazamiento afectó durante el primer trimestre a 123000 personas, y se espera que el desplazamiento forzado produzca un impacto importante sobre la economía del país. Este mismo fenómeno se debe reflejar en el núcleo familiar de las personas desplazadas, toda vez que en su mayoría proceden de las regiones más pobres del país, especialmente ubicadas en áreas rurales, y quienes derivan su sustento de actividades que requieren poca calificación profesional como la agricultura. Una vez son forzadas a migrar de una forma precipitada, apenas con unas pocas pertenencias, ingresan a los cinturones de miseria de grandes y medianas ciudades, donde sus actividades laborales usuales no tienen demanda $\mathrm{y}$, por lo tanto, deben competir con gran desventaja, en un mercado laboral afectado por la situación económica del país, y en un buen porcentaje se convertirán en desempleados o realizarán actividades como las ventas ambulantes, en las que tiene más chance de desenvolverse".

Una proyección realizada por el coDHes determinó que, en promedio, a Santiago de Cali llegan cada día tres familias desplazadas. Es una cifra alarmante sin contar con otras regiones del país como Santander, Cauca, Antioquia, Meta, Córdoba, Bolívar, Boyacá, Cesar y Norte de Santander, las cuales presentan grandes flujos migratorios. El impacto es emocional, porque no genera la felicidad como bien supremo; el vivir es un estado de desigualdad social y mental, porque los vuelve indignos de tomar labores ajenas a su origen para sobrevivir en la fabulosa ciudad. Para nadie es rara la palabra desplazado, pero sí indiferente.

Para la unidad de campo de ops en Santiago de Cali y la ong Visión Mundial, el número de familias desplazadas que recibe el municipio ha aumentado paulatinamente, llegando a un acumulado de 13677 personas, según la base de datos de la red de seguridad social a enero del 2002. Del mismo modo, la ONG Sol y Vida, ubicada en el sector de Agua Blanca, reporta que, al interrumpirse los diálogos entre las FARC y el

2. Véase Diana Carolina Cáceres Matías, supra, nota 1
Gobierno Nacional a mediados de marzo del 2002, aumentó el flujo de desplazados a Cali.

La población en condición de desplazamiento se ubica, principalmente, en los sectores de Agua Blanca en el área sur, y el sector de Laderas, en el área occidental de la ciudad. Según la ONG Visión Mundial y los líderes comunitarios de la zona, la población desplazada del distrito de Agua Blanca está representada en un número aproximado de 1000 familias, y se ubica principalmente en las siguientes comunas: 13, 14, 15, 18 y 21.

La tierra ha sido motivo de conflictos y guerras desde la conquista de los españoles, ya sean de carácter estratégico, político, de posición, económico, o bien por productividad, y se podrían seguir enumerando múltiples causas que "expliquen" el conflicto.

El desplazamiento que se ha venido presentando en la última década no es ajeno a ninguna de las posibles causas enunciadas anteriormente; familias que llegan a la capital del Valle huyendo del trágico destino que sufrieron sus vecinos, amigos e incluso algunos de sus familiares, quienes no escaparon de grupos armados y los obligaron a desprenderse de sus tierras, sus costumbres, y los llevan a afrontar viajes interminables en un hábitat totalmente extraño y al que tal vez nunca se adaptaran.

\section{Algunas miradas PARA UN FENÓMENO NO TAN PASAJERO}

El desplazamiento forzado en Colombia se ha estudiado desde diversos enfoques. Uno basado en las "historias de vida" como fuente principal para la reconstrucción histórica y periodística del fenómeno. Este plantea una postura crítica frente a las condiciones políticas, económicas y sociales que propician el desplazamiento en Colombia y se desarrolla, entre otros, en los trabajos de Alfredo Molano ${ }^{3}$ y de Germán Castro Caicedo. ${ }^{4}$

En un plano más estrictamente académico, el tema ha sido abordado desde distintas perspectivas. En primer lugar, están quienes trabajan el marco del conflicto armado interno, como los investigadores del IEPRI Jaime Zuluaga Nieto ${ }^{5}$ y Mauricio Romero. ${ }^{6}$

\footnotetext{
3. Cf. Alfredo Molano. Los años del tropel: Crónicas de la Dolencia. (1985); Entre la coca y el oro. (1990) El Áncora Editores; Desterrados. Crónicas del Desarraigo. El Áncora Editores. (2001).

4. Cf. Germán Castro Caicedo. Sin Tregua. Editorial Planeta. (2003). 5. Cf. Jaime Zuluaga Nieto. Guerra prolongada, negociación incierta: Colombia. Comp. León Roberto Briceño. Dolencia, SOciedad Y justicia en América Latina. Clacso. (2002).

6. Cf. Mauricio Romero. La politica en la paz y violencia. AnÁLISIS Político 45. Abril de 2002.
} 
Este enfoque analiza los distintos procesos políticos, incluido el desplazamiento forzado, a partir de la intensificación y degradación de la guerra y de la relación entre sus diversos actores. Para Zuluaga, la guerra que vive Colombia es el resultado de la ausencia de procesos reformistas que posibilitaran el acceso de los sectores populares a los beneficios del crecimiento económico y de la ciudadanía. A ello se suman los elevados niveles de inequidad, exclusión y la existencia de un Estado incapaz de regular los conflictos sociales, y de un sistema político que ha bloqueado el desarrollo de una democracia moderna, por privilegiar intereses individuales y no generales que correspondan a la lógica y dinámica de los cambios de la sociedad nacional. En síntesis, señala que la guerra en Colombia es síntoma de una carencia de institucionalidad democrática, situación que se considera de vital importancia para que se produzca el fenómeno del desplazamiento forzado. Para Romero, por su parte, es fundamental examinar las interacciones entre el campo político legal, así como entre las organizaciones ilegales y las estrategias de los actores regionales, con el fin de plantear coaliciones con los gobiernos locales. En esta misma línea, el investigador Felipe Vega ${ }^{7}$ publica un artículo en el que introduce el análisis entre la ciencia política y la teología, en relación con el proceso de desplazamiento forzado en el Magdalena Medio. En él expone un nuevo poder dentro de las comunidades como mecanismo de lucha y resistencia, en contra de un sistema político de muerte. El trabajo analiza cómo la experiencia de fe en estas comunidades permite entender las luchas sin violencia de personas reales tratando de vivir gracias a una nueva comprensión de la liberación del Dios de la vida.

Una segunda tendencia desde la cual se analiza el desplazamiento forzado es la que lo relaciona con la tenencia, el uso de la tierra y con las disputas territoriales. Como representantes de dichos estudios se encuentran los trabajos de Absalón Machado y Darío Montaña Fajardo. ${ }^{9}$ El primero de ellos señala que el avance de la gran propiedad, el deterioro de la mediana y la continua fragmentación de la pequeña propiedad han sido fenómenos acompañados de violencia, desplazamientos rurales y masacres constantes. La carac-

\footnotetext{
7. Cf. Darío Montaña Fajardo. Desterrados, entre el silencio y la esperanza. Desplazamiento forzado: Bio-política de la invisibilidad. Teología Xaveriana 149. Marzo del 2004.

8. Cf. Absalón Machado. La Cuestión Agraria en Colombia a FINES DEL MILENIO. El Áncora Editores. (1998).

9. $C f$. Para sembrar paz hay que aflorar la tierra. Instituto de Estudios Ambientales, IDEA, Universidad Nacional de Colombia. (1978).
}

terística de la década de los noventa es la conformación de una gran propiedad con ejércitos propios que defienden los latifundios, como en las épocas feudales y los cultivos ilícitos o zonas estratégico-militares. Como afirma Machado, "se trata, entonces, de una involución en la estructura agraria, que refleja la pérdida de domino territorial por parte de las autoridades y la acentuación de un Estado patrimonial en el que intereses privados priman sobre los de la colectividad". ${ }^{10}$ De acuerdo con Darío Fajardo, el conflicto colombiano y, por lo tanto, el desplazamiento forzado tienen sus raíces en viejos problemas no resueltos, como el de las relaciones políticas, económicas y sociales, derivadas de la gran concentración de la propiedad de la tierra.

Una tercera temática la representan los estudios del conflicto social y el desplazamiento en las regiones colombianas. Como parte de esta tendencia se puede mencionar a Orlando Gutiérrez ${ }^{11}$ y a Ricardo Vargas. ${ }^{12}$ En algunos de estos estudios se establece la conexión entre las fumigaciones y el desplazamiento forzado de colombianos. Para Vargas, por ejemplo:

Las políticas de fuerza contra los cultivos de uso ilícito generan el desplazamiento de la población asentada en una región (...). En el caso colombiano, la fumigación - al promover los desplazamientos produce cordones de miseria en cabeceras municipales que no están en capacidad de atender dinámicas demográficas de "avalancha", lo cual acentúa el desempleo, los índices de necesidades insatisfechas y promueve fenómenos de delincuencia, sobre todo, cuando las condiciones macroeconómicas afectadas por el déficit fiscal, el alto costo del capital, la crisis del sector agropecuario, la irracionalidad en la tenencia y uso de la tierra apta para la agricultura, la violencia misma limitan las posibilidades de oferta de alternativas viables en el ámbito legal. ${ }^{13}$

Otro enfoque es el que analiza los desplazamientos urbanos y tiene entre sus representantes a Gloria Naranjo y Deisy Hurtado, de la Universidad de

\footnotetext{
10. Véase Absalón Machado, supra, nota 8. Pág. 56. 11. Cf. Orlando Gutiérrez. Estructura de La PROPIEDAD RURAL Y Sistema de TenENCIA DE SIERRA EN SANTANDER. Funprocep, alop. (1990).

12. Cf. Ricardo Vargas (Comp.). Drogas, poder y Región eN COLOMBia, IMPACTOS LOCALES Y CONFLICTOS. Volumen 2. CINEP. (1994).

13. Véase Ricardo Vargas. Drogas, seguridad y democracia en América Latina. Jairo Estrada Álvarez Comp. El Plan Colombia y LA INTENSIFICACIÓN DE LA GUERRA. Universidad Nacional de Colombia. (2002).
} 
Antioquia. Para estas investigadoras, el desplazamiento urbano produce un impacto sobre la subjetividad y la transformación de las coordenadas espacio-temporales de los desplazados, que son claves para entender cómo se da "el progresivo cambio del significado del espacio y del tiempo y sus profundas consecuencias en el mundo de los valores, actitudes, las motivaciones, los estilos cognitivos". Estas situaciones inducen a "nuevas estrategias, nuevos retos, tensiones y negociaciones en la ciudad". Este enfoque pretende superar las visiones estigmatizadoras sobre los migrantes y desplazados por la violencia, y propone reconocer cómo los aportes culturales y sociopolíticos de los nuevos habitantes que llegan contribuyen a la configuración de las ciudades. ${ }^{14}$

El tema del desplazamiento forzado de indígenas, afrocolombianos y campesinos lo desarrolla Luís Guillermo Vasco. ${ }^{15}$ De acuerdo con él, la expansión de los conflictos en los territorios indígenas tiene que ver generalmente con las ventajas estratégicas de dichos territorios, que son usurpados por los narcotraficantes, la insurgencia y los paramilitares; por la expansión de cultivos ilícitos de coca y amapola; por la acción de los terratenientes y, más recientemente, por las fumigaciones. Este enfoque es compartido por la Defensoría del Pueblo, que sostiene que el desplazamiento forzado indígena implica: "una degradación acelerada de la vida de la población étnica, dado que el desarraigo territorial altera gravemente su identidad, integridad y cultura: situación que plantea una impotencia, a tal punto que el ordenamiento jurídico nacional e internacional que los protege resulta insuficiente". ${ }^{16}$

Los procesos organizativos y de resistencia de la población desplazada, sus alcances, limitaciones y retos, son estudiados por Juan Manuel Bustillo. ${ }^{17}$ Según este autor, la resistencia de la población desplazada

14. Véase Gloria Naranjo. El derecho a la ciudad. Migrantes y desplazados en las ciudades colombianas. Desplazamiento forzado Y RECONFIGURACIONES URBANAS. EL CASO DE MEDELLÍ́N Y DEL Área metropolitana 1992-2002. Instituto de Estudios Políticos, Universidad de Antioquia. Pág. 1.

15. Citado por Ernesto Restrepo Tirado. Desplazamiento forzado $v$ reconstitución cultural. Éxodo, patrimonio e identidad. 5 CÁTEDRA DE HISTORIa Museo nacional. (2000). El profesor Vasco ha publicado más de 11 libros profusamente ilustrados sobre las sociedades embera y guambiana, el movimiento y la lucha indígenas, teoría antropológica y marxismo, entre otros temas.

16. Véase Defensoría Delegada para Indígenas y Minorías Étnicas. INFORME, JULIO DE 2001. Disponible enwww.disaster-info.net/.../ informes/.../jul2001/default.htm

17. Véase Juan Manuel Bustillo. La organización de la población desplazada y la reconstrucción del tejido social. Desplazamiento FORZADO INTERNO EN COLOMBIA: CONFLICTO, PAZ Y DESARROLLO. ACNUR-Coneys. (2001) ha tenido antecedentes en las movilizaciones y protestas campesinas cívicas e indígenas. Por lo general, el punto que siempre reclaman es la presencia estatal por medio de obras de infraestructura básica, salud y educación. Debido a las fumigaciones, se han dado paros importantes, como el realizado entre finales de 1994 y comienzos de 1995, y el de 1996, que congregó a aproximadamente 57000 campesinos, en su mayoría cultivadores de coca, quienes se desplazaron a los cascos urbanos de Mocoa, Puerto Asís, San Miguel y la Hormiga. En aquella ocasión, demandaban el cumplimiento de los acuerdos firmados en el AGRO de 1995, la suspensión de las fumigaciones y la obtención del reconocimiento social de la problemática de los pequeños cultivadores de hoja de coca. Quienes trabajan en este tema, recopilan los antecedentes históricos y llevan a cabo los análisis de la causal y las consecuencias de los hechos que llevan a la resistencia en la que están involucrados los desplazados.

Por otra parte, se encuentra la cooperación internacional y las experiencias de acompañamiento a la población desplazada, temas estudiados por Rickard Nordgren..$^{18}$ Desde una perspectiva crítica, señala que el papel de las organizaciones internacionales está relacionado con las políticas de los Estados Unidos, enlazadas a su vez con los intereses económicos de las multinacionales. Las situaciones de conflicto territorial, la agudización de las crisis de Colombia y sus países vecinos, y el desplazamiento transfronterizo se analizan y evalúan frente al desarrollo de los grandes proyectos políticos y económicos que promueven inversiones en zonas estratégicas, tales como las zonas de conflicto. Entre estos proyectos se encuentran el Plan Colombia, el Plan Puebla Panamá, la IRA y el ALCA. Los estudios del desplazamiento forzado se relacionan con los intereses antes mencionados y tienen como elementos comunes la evaluación de los potenciales impactos de estos planes globales en todos los aspectos de la vida económica, política, social, cultural y ambiental. ${ }^{19}$

\footnotetext{
18. Citado por Consuelo Ahumada Beltrán. ¿Responde realmente la cooperación internacional a lo que Colombia necesita? DESPLAZAMIENTO FORZADO INTERNO EN COLOMBIA: CONFLICTO PAZ Y DESARROLLO. MEMORIAS SEMINARIO INTERNACIONAL, ACNUR-CODHES. (Junio del 2000).

19. Véase Sheila Gruner. Desplazamiento forzoso, políticas externas y comunidad internacional. Destierro y Desarraigos, MeMORIAS DEL H SEMINARIO INTERNACIONAL, Desplazamiento: IMPLICACIONES Y RETOS PARA LA GOBERNABILIDAD, LA DEMOCRACIA Y LOS DERECHOS HUMANOS. Bogotá: CODHES, OI M. (Septiembre de 2002)
} 
El tema de las fronteras y el desplazamiento ha sido estudiado por entidades como CODHES, ${ }^{20}$ el International Crisis Group, ${ }^{21}$ el Observatorio Andino de la Pontificia Universidad Javeriana, ${ }^{22}$ y la Conserjería de Proyectos. ${ }^{23}$ Esta línea temática estudia el desplazamiento en las zonas de fronteras en conexión con las políticas internacionales. Enmarcados en este enfoque, el Centro Editorial Javeriano CEJA, con el auspicio de la Fundación Honrad Adenauer Stiftung, publica una investigación sobre el desplazamiento forzado de colombianos hacia el Ecuador en el contexto del Plan Colombia. El enfoque del desplazamiento forzado que se plantea en el trabajo parte del análisis de dicho fenómeno en el marco de los cambios en las relaciones internacionales de la Región Andina, de las políticas derivadas del nuevo orden mundial, y de la forma como dichos cambios y políticas han afectado los procesos políticos, económicos, sociales y culturales de los países de la región y sus fronteras en los últimos tiempos. Este enfoque integral pretende superar las limitaciones de las visiones anteriormente descritas, que, en términos generales, no abordan el fenómeno del desplazamiento forzado en dicho marco internacional. Ahumada, al continuar con esta perspectiva de investigación ${ }^{24}$-en la línea de relaciones internacionales y América Latina e integración-, realiza un trabajo sobre la incidencia de las políticas de seguridad en la región andina, la respuesta de los actuales gobiernos de Colombia y Venezuela a estas políticas, y cómo se reflejan las relaciones bilaterales en los problemas fronterizos y en el desplazamiento transfronterizo de colombianos.

Los analistas del conflicto armado señalan que el país está "sobre-diagnosticado", y que es hora de empezar a poner en práctica las conclusiones de los estudios. Sin embargo, en lo concerniente a la dinámica del desplazamiento forzoso y las migraciones en el suroccidente

20. Véase codhes. Iniciativa Regional Andina, fronteras y CONFLicto ARMADO INTERNo EN COLOMBIA. CODHES. (2001); $y$ CODHES. CARACTERIZACIÓN SOCIOECONÓMICA Y POLÍTICA DE LAS ZONAS DE FRONTERA DE COLOMBIA. CODHES (2002).

21. Véase International Crisis Group. Colombia y sus vecinos: LOS TENTÁCUlOS DE LA INESTABILIDAD. International Crisis Group. (2003)

22. Véase Consuelo Ahumada et al. El DESPlazAmiento FORZADO DE COLOMBIA HACIA LA REGIÓN ANDINA Y SU IMPACTO SOBRE LA SITUACIÓN POLÍTICA REGIONAL. COMUNIDAD ANDINA Y MERCOSUR EN LA PERSPECTIVA DEL ALCA. Centro Editorial Javeriano-CEJA. (2003).

23. Véase Consejería de Proyectos. Asilo y refugiados en las FRONTERAS DE COLOMBIA. (2003).

24. Consuelo Ahumada. El DESPLAZAMIENTo FORZAdo DE COLOM BIANOS HACIA VENEZUELA EN EL CONTEXTO DE LAS PRIORIDADES DE EsTAdos UNIDOS EN LA REgIÓN ANDINA Y DEL DETERIORO DE LAS RELACiONES ENTRE Venezuela y Colombia (2000-2003). colombiano, el Estado del arte indica lo contrario. ${ }^{25}$ En efecto, a pesar del impacto histórico y coyuntural de los desplazamientos en la conformación territorial de Cali y el suroccidente - tal como lo muestran algunos estudios-, no se registran programas de investigación sistemáticos para la región, con excepción del trabajo realizado en 1997 por la Arquidiócesis de Cali y el CODHEs sobre desplazamiento forzoso, ${ }^{26}$ y por la Universidad del Valle sobre las migraciones hacia Cali. Se destacan los trabajos de Fernando Urrea, ${ }^{27}$ publicados entre 1994 y $1999,{ }^{28}$ especialmente en su participación como ensayista en Dinámica del poblamiento y algunas características de los asentamientos populares con población afrocolombiana en el oriente de Cali. A este autor, además, se le deben las estadísticas de caracterización y cuantificación del llamado "desplazamiento racista”, que corresponden al $54 \%$ de población afrocolombiana por encima de los otros grupos raciales, ${ }^{29}$ así como algunos estudios sociohistóricos que abordan el tema del desplazamiento forzoso como un efecto directo de los ciclos de violencia que ha sufrido la región suroccidental en el siglo xx..$^{30}$ Menos aún, se han sistematizados las experiencias que de una $\mathrm{u}$ otra forma han dado respuesta a este fenómeno. Lo único que existe en este sentido (publicado) es el directorio de la oferta institucional para la atención a la población desplazada por la violencia política, elaborado por el Comité Internacional de la Cruz Roja en 1998. ${ }^{31}$

Por último, cabe destacar los estudios emprendidos por otros sectores de la academia caleña para la comprensión de las violencias urbanas y rurales del

25. Sobre el estado del arte de los estudios con relación al tema, CODHES anota: "Los estudios sobre el desplazamiento: La problemática del desplazamiento ha empezado a estudiarse muy recientemente en el país". Véase Mujer desplazada: violencia y discriminación. UN País Que Huye. Desplazamiento y Violencia en UNA Región FRAGMENTAda. (1997). Pág. 151

26. Véase www.codhes.org/index.php?option=com_docman\&task

27. Véase Fernando Urreay Camilo Domínguez.(Edit.).Desplazados, MIGRACIONES INTERNAS Y REESTRUCTURACIONES TERRITORIALES. Observatorio Socio Político y Cultural. Centro de Estudios Sociales. Facultad de Ciencias Humanas Universidad Nacional de Colombia. (1999).

28. $I d$.

29. Véase César Rodríguez Garavito. ¿Colombia Racista? 21 de mayo del 2008. elespectador.com. Disponible en http://www.elespectador.com/impreso/tema-del-dia/articuloimpreso-colombia-racista 30. Véase Conflicto, S. D. R. Informe Estructural Situación de Riesgo por Conflicto Armado en la Costa Pacífica Caucana Municipios de Guapi, Timbiquí y López de Micay. (2014). Disponible en wikileaks.org/leak/bolivariana/vecka52/ semanal.../semana44.doc Consulta en línea Octubre de 2007. 31. Véase Marcela Salazar, Andrea Duque, Yulieth Monsalve. Conflicto, violencia y convivencia social como área emergente para el trabajo social. ELEUTHERA, 2007, p. 130-141. 
Valle y el Cauca (CIDSE y CISALVA de la Universidad del Valle). No obstante, la mención y el análisis del desplazamiento son, las más de las veces, tangenciales. El desplazamiento forzoso en Colombia y el suroccidente se enmarca en una prolongada, intensa, irregular, heterogénea e inconclusa violencia política, porque desde la época de formación de la República hasta hoy, Colombia ha experimentado, en relación con el conjunto latinoamericano, un elevado número de guerras civiles, ${ }^{32}$ levantamientos populares, revueltas, insubordinaciones armadas, oleadas de represión estatal y asesinatos políticos. Estas expresiones han tenido una incidencia y unos ritmos específicos en la generación del desplazamiento forzoso a través de la historia, de los cuales ni Cali, ni el suroccidente colombiano han escapado. El tipo de ciclo de violencia de cada periodo influyó en las posibilidades de retornar, de reasentarse o de integrarse a cierta comunidad ${ }^{33}$ receptora por parte de los desplazados, como se verá más adelante.

Debido a que la situación de desplazamiento no es ajena a los colombianos, han surgido varios proyectos y artículos sobre este tema, sin embargo, dicho estudios son de carácter nacional. Entre estos se destacan los siguientes.

\section{A. codhes. Boletín de la Consultoría de los Derechos Humanos. Julio 19 de 2005; 60.}

Es el segundo informe sobre desplazamiento forzado, derechos humanos y conflicto armado en Colombia correspondiente al segundo trimestre del 2005, que se presenta públicamente en Cali, capital del departamento del Valle del Cauca y principal centro urbano del litoral pacífico colombiano (...) Justamente en buena parte del territorio del litoral pacífico están ocurriendo los hechos que marcan el escalamiento de la guerra interna y, por supuesto, la expansión de la crisis humanitaria provocada por el desplazamiento forzado de más de 32.373 personas en los departamentos de Nariño, Cauca, Valle del Cauca y Chocó, es decir, un promedio de 359 personas cada día que se sitúan en Cali como ciudad receptora. ${ }^{34}$

En este informe cODHES, se reafirma el propósito de insistir en la adopción de mecanismos para proteger

32. Cf. Gonzalo Sánchez Gómez. GuERRA Y POLÍTICA EN LA SOCIEDad colombiana. El Áncora Editores. (1991). Pág. 26.

33. Id. Pág. 27.

34. Véase Codhes. Boletín de la Consultoría de los Derechos Humanos. Julio 19 de 2005; 60. a la población civil, aun en las circunstancias inevitables de la continuidad del conflicto, exigiendo a todas las partes enfrentadas que observen el derecho internacional humanitario, los derechos humanos y las normas que protegen a la gente en estado de indefensión.

\section{B. PNUD. La convivencia y la paz: condiciones} para la inclusión. HACIA UN VALLE DEL CAUCA INCLUYENTE Y PACÍFICO. INFORME REGIONAL DE Desarrollo Humano IDH-VAlle 2001. PNUd. (2008).

El capítulo del informe expone cómo el reto es alcanzar una sociedad respetuosa de los derechos humanos, principalmente del derecho a la vida y a la integridad, en un marco de convivencia integrador e incluyente, en referencia al problema, a las causas y las consecuencias del desplazamiento forzado. Este informe es útil porque además de establecer el problema, propone soluciones para el departamento del Valle del Cauca, y por tanto para Cali, la ciudad receptora del mayor número de población desplazada en el departamento.

\section{Fedesarrollo. La ley de víctimas una reparación pendiente. ECONOMÍA Y Política. Abril 2010; 60. Págs. 1-6.}

El artículo hace referencia a la situación del país y al proceso de consolidación del monopolio de la fuerza en todo el territorio por el cual atraviesa, y expone lo siguiente:

El éxito del proceso de pacificación dependerá de las garantías de no repetición y de justicia para las víctimas, de mecanismos adecuados para resolver las trampas de pobreza derivadas del marginamiento de los desplazados en las zonas urbanas, y de un proceso de reinserción que minimice la conversión a otras formas de violencia (...) Los procesos de victimización son, en su mayoría, recientes. Las desapariciones forzadas y el desplazamiento forzado han aumentado, siendo el 2008 el segundo peor año desde $1985 .^{35}$

Dicho informe también hace un resumen legal sobre las normas vigentes respecto al tema de víctimas con un enfoque económico, lo cual es de gran utilidad para comprender que la situación de desplazamiento en Colombia es un problema de gran envergadura.

35. Véase Fedesarrollo. La ley de víctimas una reparación pendiente. Economía y Política 6o. Abril 2010. Pág. 4 
Estos informes son un gran apoyo para el presente trabajo porque presentan datos significativos que permiten relacionar la población en situación de desplazamiento con estudios hechos a nivel nacional, y así realizar un énfasis a nivel municipal, ya que si bien es cierto que hay muchos artículos sobre el desplazamiento, no se conoce análisis alguno sobre los planes y programas para prevención y atención del desplazamiento forzado que ha realizado la Administración Municipal de Santiago de Cali, de acuerdo con las normas preexistentes para esta materia.

\section{MARCO TEÓRICO}

La presente sección ${ }^{36}$ comienza con el recuento de algunas definiciones sobre el desplazamiento y el refugio, formuladas por las organizaciones internacionales que se ocupan del tema. Enseguida se sintetizan algunos de los principales enfoques metodológicos y teóricos sobre el problema del desplazamiento forzado.

En cuanto a las definiciones sobre el tema, se señala que en el informe analítico del Secretariado General sobre Desplazados Forzosos, y en un estudio del representante del secretario general para asuntos de derechos humanos relacionados con desplazados forzosos, la Comisión de Derechos Humanos de las Naciones Unidas define a los desplazados como:

Personas o grupos de personas que se han visto forzadas u obligadas a escapar o huir de su hogar o de su lugar de residencia habitual, en particular como resultado de un conflicto armado, situaciones de violencia generalizada, violaciones de los derechos humanos o catástrofes naturales o provocados por el ser humano y en su propio país. ${ }^{37}$

Por otra parte, el artículo 1 (A) (2) de la Convención sobre el Estatuto de los Refugiados y el Protocolo del Estatuto de los Refugiados, define a un refugiado como a cualquier persona que tenga:

36. Se toman como base los aportes realizados por la profesora Consuelo Ahumada y por Álvaro Moreno Duran, en la publicación de 9 de septiembre de 2005 del portal LA Insignia. Véase Consuelo Ahumada y Álvaro Moreno Duran. Prioridades del nuevo orden mundial y desplazamiento forzado de colombianos hacia Ecuador (II). LA Insignia. Diciembre del 2005. Disponible en http://www.lainsignia.org/2005/diciembre/ibe_030.htm

37. Véase OACNUDH. ACV-R, CODFES Comp. COMPILACIÓN SOBRE DESPLAZAMIENTO FORZADO. NORMAS DOCTRINAS Y JURISPRUDENCia nacional e internacional. (Diciembre de 2001). Pág.19.
Fundados temores de ser perseguida por motivos de raza, religión, nacionalidad, pertenencia a determinado grupo social u opiniones políticas, se encuentrefuera del país de su nacionalidad y no pueda o, a causa de dichos temores, no quiera acogerse a la protección de tal país; o que careciendo de nacionalidad y hallándose, como consecuencia de tales acontecimientos, fuera del país en donde antes tuviera su residencia habitual, no pueda o, a causa de dichos temores, no quiera regresar a él. ${ }^{38}$

De los conceptos anteriores se deduce que, a diferencia del desplazado, el refugiado no solo ha cruzado una frontera intencionalmente reconocida, sino también ha obtenido el estatus de refugiado por parte del gobierno del país al cual llega.

En cuanto a las instituciones que se han ocupado del tema de los desplazados en el ámbito internacional, se encuentran ACNUR, ${ }^{39}$ la OIM, ${ }^{40}$ la Cruz Roja Internacional, la oEA, el Consejo Internacional de Agencias Voluntarias y el Consejo Mundial de Iglesias. En términos generales, dentro de una visión muy limitada, estos organismos relacionan el problema del desplazamiento forzado en Colombia con el reconocimiento del Derecho Internacional Humanitario (DIH), y con el respeto por los derechos humanos en el país. La Cruz Roja, por ejemplo, lo hace a partir de su principio fundamental de neutralidad, que rige la misión del Movimiento internacional y de la Media Luna Roja. ${ }^{41}$

El análisis institucional en Colombia del problema de los desplazados se inició a partir del documento

\footnotetext{
38. Id. p.26.

39. A mediados de 1997, el Gobierno de Colombia solicitó a la ACNUR prestar su asesoría a las instituciones nacionales encargadas de atender a la población desplazada, para lo cual era preciso que se estableciera una oficina en el país. Con el consentimiento del Secretario General de las Naciones Unidas, la ACNUR respondió favorablemente a la solicitud del Gobierno de Colombia y, en junio de 1998, abrió una oficina en Bogotá con el propósito de contribuir al fortalecimiento de la capacidad nacional de respuesta al problema del desplazamiento. Posteriormente fueron creadas otras tres oficinas en terreno. Véase http://www.acnur.org/crisis/colombia/index.php

40. La оiм, una organización intergubernamental creada en 1951, está consagrada al principio según el cual la migración en condiciones humanas y de forma ordenada beneficia a los migrantes y a la sociedad. Véase http://www.oim.org.co/

41. Véase Richard Perruchoud. Derechos y deberes internaCiONALES DE LAS SOCIEDADES NACIONALES Y DE LA MEDIA LUNA Roja. Instituto Henry Dunant. (1982); Estatutos de LA Sociedad Nacional de la Cruz Roja Colombiana aprobados por la CONVENCIÓn Nacional EXTraordinaria-Estatutaria. (Febrero de 1996); y Los Convenios de Ginebra del 12 de agosto de 1949. CICR. (2012).
} 
Conpes N. 2804 del 13 de septiembre de 1995, ${ }^{42}$ que se constituye en el documento por el cual el Estado colombiano reconoce la responsabilidad de diseñar las políticas públicas que garanticen la atención integral a la población desplazada y la protección de sus derechos, $y$ en el que se establecieron los lineamientos principales para atender el fenómeno. En este documento ${ }^{43}$ se definieron como objetivos centrales la atención a la población ya desplazada, así como la neutralización de las dinámicas de la violencia que generan fenómenos de desplazamiento. Estos objetivos pretendían ser cumplidos a partir de cuatro estrategias: prevención, atención inmediata, consolidación y estabilización socioeconómica y, finalmente, comunicación e investigación. En el proceso de aceptación del desplazamiento forzado como resultado de la violencia política en el país, surgió la Ley 387 del 18 de julio de 1997, mediante la cual se reglamentó el Programa para la Atención Integral a la población Desplazada.

Esta ley busca adoptar medidas para la prevención del desplazamiento forzado, así como la atención, protección, consolidación y estabilización socioeconómica de los desplazados internos por la violencia en Colombia. ${ }^{4}$

El Estado acepta que debido a la inexistencia de un formato único para la toma de declaración y a la diversidad de concepciones en los procedimientos para la misma, mucha información tomada desde 1995 venía incompleta, lo que hace que muchas variables no presenten los datos esperados: "Sin Información". Hasta el año de 1999 la Dirección General para los Derechos Humanos del Ministerio del Interior tuvo a su cargo el manejo del registro de población desplazada.

42. "El Gobierno Nacional, consciente de la magnitud de la problemática del desplazamiento interno en Colombia y sus graves efectos sobre los derechos humanos, renueva su compromiso con la población desplazada, incluida aquella ubicada en las zonas de frontera, por causas asociadas a la violencia. Igualmente, reafirma que esta política busca crear, las condiciones para prevenir la ocurrencia del desplazamiento y facilitar el retorno voluntario de esta población a su lugar de origen". Véase Presidencia de la República. Una Nueva Política por la Vida. (Septiembre 9 de 1994). Pág. 12. Véase también DNP. El Salto Social. Plan Nacional de Desarrollo. En Fabio Sánchez. LA DISTRIBUCión DEL INGRESO EN COLOMbIa: TeNDENCIAS RECIENTES Y RETOS DE LA POLÍtica PÚBLICA. TM Editores. (1998). Págs. 174-177; y Documento CONPES 2804. Septiembre 13 de 1995.

43. Véase Acción Social. Cifras sobre el Desplazamiento eN Colombia. Disponible en www.accionsocial.gov.co/SUR/ Instructivo.pdf

44. Véase Presidencia de la República de Colombia. Los DesplazADOS, ESA COLOMBIA QUe NO PODEMOS IGNORAR. (Abril de 1998).
La dinámica del desplazamiento y el proceso de atención a la población desplazada fueron mostrando la necesidad de introducir nuevas variables al manejo de la información y así enriquecer cualitativamente el sistema de registro.

A partir del año 2000 se comienza a tomar de manera detallada la información de los desplazamientos masivos y se implementan los procedimientos para alimentar la información diferenciándola de los desplazamientos individuales.

En Abril del 2001 se pone en funcionamiento el Sistema Único de Registro a nivel nacional y se implementan los procedimientos para la actualización de la base de datos tanto a nivel territorial como nacional. De igual forma, por la misma época se distribuyen los formatos de declaración, valoración, caracterización y seguimiento que permiten la unificación de criterios para la captura de la información.

En Junio de 2001 se inicia un proceso de capacitación nacional a funcionarios del ministerio público con el propósito de unificar los criterios para la toma de declaración, diligenciar el Formato Único de Declaración y estandarizar los procedimientos de toma de declaraciones. ${ }^{45}$

Los enfoques que han primado en estos análisis y permiten concretar el estado del arte son tres. A continuación, se exponen de manera breve.

\section{A. Análisis sociohistórico}

El análisis sociohistórico presenta un enfoque de larga duración e investiga el desarrollo territorial de Colombia en el desempeño de los conflictos sociales que han generado violencia, combinando los niveles económico, político y sociocultural del análisis histórico. Para este proyecto, estos estudios se constituyen en verdaderas vetas para entender el sentido del actual movimiento migratorio por causa de la violencia hacia Cali y sus impactos, en la medida en que analizan los procesos regionales de poblamiento articulando las dimensiones económica, política y sociocultural, no como variables agregadas, sino como componentes interrelacionados del inacabado proceso de construcción del Estado y la nación colombianos. Lo anterior se profundizará más adelante. $^{46}$

\footnotetext{
45. Véase Acción Social, supra, nota 43

46 Fernán González S. del cineP expresa claramente las dimensiones de análisis de esta corriente: "Nuestra investigación busca interpretar las actuales violencias dentro del proceso de larga duración de la construcción de la sociedad y del Estado colombianos, como caldo de cultivo donde se insertan las opciones violentas de
} 


\section{B. Análisis socioeconómico}

La línea socioeconómica se centra en las dos últimas décadas, y en las dimensiones socioeconómica y sociodemográfica de las migraciones. En general, especula sobre la intensidad y el impacto de las migraciones en la economía y estructura sociodemográfica de la población asentada en Cali. Sin embargo, deja por fuera dimensiones claves de las migraciones, tales como la político-institucional y la sociocultural, así como la tipología de migrantes para Cali. Fernando Urrea, de la Facultad de Ciencias Económicas y Sociales de la Universidad del Valle, es el mejor representante de esta corriente, la cual sobresale por su rigurosidad cuantitativa. Estos estudios servirán para contextualizar la dinámica de desplazamiento forzoso en Cali en el conjunto del movimiento migratorio, principalmente desde la década de los noventa.

\section{Análisis descriptivo o panorámico}

La dinámica de los desplazados, en particular a partir de la década de los ochenta, solo se destaca en el estudio pionero de la Arquidiócesis de Cali y el codHes, Los desplazados en Cali: entre el miedo y la pobreza, obra publicada en 1997. No obstante, en esta se esbozan algunas de las principales características de la población desplazada, así como los factores causales de la misma, dejando valiosos interrogantes por desarrollar. Por otro lado, la definición de desplazado que asume este estudio se mueve entre una definición mínima, acorde con la contemplada por la Ley 387 del 18 de julio de 1997, y una máxima, en la que incluirán las migraciones por razones económicas y por desastres naturales. Asimismo, entre los factores mencionados como detonantes de los desplazamientos, señalan la violencia urbana difusa, encabezada por pandillas y grupos delincuenciales que no son actores estrictamente políticos

antiguos y nuevos actores sociales, que se entrecruzan y refuerzan mutuamente hasta hacerse indistinguibles unas de otras, llegando a producir la imagen de violencia omnipresente, indiferenciada y caótica. Para ello se mueve en tres dimensiones complementarias entre sí: a. Seguimiento de los procesos de poblamiento e integración interna, geográfica y económica, de las diversas regiones y de su relación con el mercado mundial. b. Seguimiento de los procesos de cohesión social y de socialización política (creación de redes políticas) en relación con la construcción de las instituciones nacionales. c. Análisis de los imaginarios colectivos de identidad y pertenencia en los diferentes niveles y de los sistemas de valores desde los cuales se perciben, analizan y juzgan los acontecimientos y conflictos de nuestra sociedad". Véase Tradición y Modernidad en la Política Colombiana. Violencia en la Región Andina. CineP, APEP. (1994). Pág. 1 del conflicto armado colombiano, mas sí factores generadores de violencia y desplazamiento intraurbano. Sin desconocer estos fenómenos, la crítica pertinente a este estudio agrupa bajo el término "desplazado" estas especificidades. Habría entonces que reconstruir las clasificaciones (desplazados por violencia política, por violencia no política, prófugos de la justicia, exiliados, migrantes, damnificados, retornados, etc.), evitando por esta vía las generalizaciones que pueden dificultar el entendimiento de la complejidad de la dinámica. Con base en una serie de encuestas realizadas en los barrios de Cali, se ofrece entonces una visión global y panorámica de las posibles tendencias, en lo referente a la caracterización de esta población.

El desplazamiento forzoso de la población civil, en términos generales, puede decirse que no es un fenómeno nuevo en el panorama político nacional. Por el contrario, el actual conflicto interno armado, detonante del desplazamiento forzoso, hunde sus raíces más próximas y significativas en la época de la Violencia (1948-1966), uno de los periodos más violentos de la historia colombiana, así como del suroccidente del país. Este periodo es comparado y equiparable a la época comprendida entre 1980 y 1992, durante la cual se desarrolla y estructura el narcotráfico con oleadas de terrorismo, lo que conlleva a la implementación del estatuto de seguridad durante el gobierno de Julio Cesar Turbay Ayala (1978-1982), ${ }^{47}$ quien dictó un Estatuto de Seguridad ${ }^{48}$ en ejercicio del artículo 121 de la Constitución Nacional de 1886, vigente para esa época, con el fin de contrarrestar la actividad subversiva y de narcotráfico. Este estatuto fue objeto de severas

47. Véase http://web.presidencia.gov.co/asiescolombia/presidentes/62.
htm
48. Jairo Ramírez Luis, secretario ejecutivo del Comité Permanente por la Defensa de los Derechos Humanos, sostiene: "El Estatuto de Seguridad se trata, en cierta medida, de la recopilación metódica de decretos dictados por diferentes gobiernos, en América Latina y en Colombia, en función del Estado de sitio, que pese a su naturaleza temporal, impone penas prolongadas para la sanción de determinados delitos que afectan el orden público, y extiende la jurisdicción militar para el enjuiciamiento de civiles que no se encuentren al servicio de las Fuerzas Armadas. Es la puesta en marcha de manera concreta de la doctrina de la seguridad nacional y la democracia restringida propugnada por el gobierno norteamericano para el mantenimiento de las condiciones estructurales de la dependencia sin tener que recurrir a la instauración de regímenes militares sino a través del Estado de sitio permanente, la militarización de la justicia, la censura de los medios de comunicación, la intervención y ocupación militar de las universidades públicas, la sujeción de la administración de justicia al ejecutivo". Véase Katherine Córdoba y Marcela Vela Quiroz.. LA PARTICIPACIÓN POLÍTICA DE EXCOMBATIENTES DE LAS FARC-EP EN EL PROCESO DE JUSTICIA TRANSICiONAl en Colombia. (2017). Disponible en cmap.upb.edu.co/ servlet/SBReadResourceServlet 
críticas dentro y fuera del país. Durante su administración, se vivieron momentos críticos en Colombia, como el robo de más de cinco mil armas del Cantón Norte de Bogotá por parte del Movimiento 19 de Abril, y la toma de la Embajada de la República Dominicana en Bogotá durante 61 días, por parte del mismo grupo guerrillero. De igual forma, se recrudeció el secuestro y la extorsión y surgió la agrupación armada Muerte a Secuestradores (MAS). En marzo de 1981, se firmó la "ley de amnistía", orientada a facilitar la entrega de ciudadanos levantados en armas, pero no tuvo gran acogida. Luego, en noviembre de ese mismo año, con base en una propuesta del expresidente Lleras Restrepo se constituyó la primera Comisión de Paz, que se desintegró en mayo del siguiente año.

Durante este periodo, surge como figura política Luís Carlos Galán. ${ }^{49}$ Era un joven liberal que se revelaba contra las formas de gobierno que había adquirido en el liberalismo. Por eso funda el Nuevo Liberalismo. Para las elecciones del 82, la coyuntura política fue así: López Michelsen como candidato por el liberalismo tradicional, Galán, por el Nuevo Liberalismo, y Belisario Betancur por el Partido Conservador. Este último fue quien llegó al poder.

El posterior gobierno de Belisario Betancur, entre 1982 y 1986, se caracterizó porque su política va a ser contraria a la de Turbay en cuanto a la intervención de los Estados Unidos. Detiene la represión militar y el baño de sangre del gobierno de Turbay. Promueve un tratado de paz con las guerrillas, teniendo en cuenta su debilidad. Firma amnistías. Las farC negocian con conservadores solo porque se sienten traicionadas por los liberales. La guerrilla se aprovecha de la buena voluntad del gobierno y se fortalece nuevamente. El M-19 se toma el Palacio de Justicia. ${ }^{50}$ Este, que parecía uno de sus golpes espectaculares, se convierte en una masacre y pierde la legitimidad que había ganado entre

49. Galán murió víctima de un atentado el 18 de agosto de 1989. Véase Juan Lozano Ramírez. Luís Carlos Galán. Revista Credencial Historia 37. Enero de 1993. Disponible en http://108.168.234.58/ blaa/?q=blaavirtual/revistas/credencial/enero1993/enero5.htm 50. El 6 de noviembre de 1985 un comando de 40 integrantes de la organización guerrillera Movimiento "19 de Abril" (M-19) se tomó el Palacio de Justicia, corazón del poder judicial, en el centro de Bogotá. Tomaron como rehenes a todos los ocupantes del Palacio, entre ellos a los magistrados de la Corte Suprema de Justicia. Era el desenlace de un frustrado proceso de paz que se había iniciado en el gobierno de Belisario Betancur dos años antes y que había logrado acuerdos con el M-19, y otros dos grupos guerrilleros, las Fuerzas Armadas Revolucionarias de Colombia (FARC) y el Ejército Popular de Liberación (EPL), acuerdos que se desbarataron por el incumplimiento de las partes. Véase Olga Behar. Noches DE HUMO: cómo Se Planeó y ejecutó la toma del Palacio de Justicia. Planeta. (1988). las clases sociales pobres del país. Colombia, durante este periodo, presencia de manera atónita cómo las FARC se fortalecen, además de que el auge de la cocaína se da en la década de los ochenta. Pablo Escobar, reconocido narcotraficante y benefactor social, llega a ser representante a la cámara. Con él en el poder, se fortalecen los productores y traficantes de cocaína.

El resultado del gobierno no es positivo debido a que recibió un país con guerrillas débiles y lo entregó conguerrillas fortalecidas. Después dehaber rechazado la ayuda de Estados Unidos, tuvo que volver a solicitarla, y entregó el país con un nuevo enemigo: el narcotráfico, que genera acciones como comprar tierras y se convierten en los nuevos terratenientes del país (sobre todo en el Magdalena Medio). Asimismo, las FARC, que luchan contra los terratenientes comienzan a secuestrar y extorsionar a los narcotraficantes. Estas acciones se convierten en una muy buena fuente de financiación para las guerrillas.

La investigación se aborda desde el modelo sociojurídico, que concibe la eficacia del derecho en sociedad, los problemas sobre la técnica jurídica y la implementación del derecho, entendiéndose el derecho como un instrumento para el desarrollo y la solución de problemas sociales. Tal y como lo expresa Manuel Atienza, "los instrumentos jurídicos son un conjunto de herramientas y procedimientos discursivos mediante los cuales se intenta resolver una serie de problemas, de conflictos sociales." ${ }^{51}$ Desde un enfoque del derecho como argumentación y desde la perspectiva del sicologismo y el realismo jurídico, hay que tener en cuenta que la visión instrumental pragmática es fundamental para el desarrollo de este trabajo. El trialismo jurídico del derecho es un intento - como una técnica- para resolver ciertos problemas prácticos, cuya hermenéutica es la resolución de los problemas prácticos. El problema práctico en cuestión es el desplazamiento forzado que, bajo la perspectiva de Atienza, es materia de análisis para el derecho, porque este "es una técnica para resolver los problemas prácticos” (2000, p. 65).

En relación con el fenómeno del desplazamiento forzado, se aborda "La teoría de los Derechos $\mathrm{Hu}$ manos", construida desde la declaración universal de los mismos por la Organización de Naciones Unidas $(\mathrm{ONU}) .^{52}$

51. Véase Manuel Atienza. Derecho y argumentación. Universidad Externado de Colombia. (1997).

52. Véase Adrian Onu, Thomas Pohl, Hans Krause y Silvia Bulfone Paus. Regulation of il-15 secretion via the leader peptide of two IL-15 isoforms. The Journal of IMMUNOLOGY, 1997, 158(1). Págs. 255-262. 
Esta teoría es explícita en quelos derechoshumanos son derechos inherentes a todos los seres humanos, sin distinción alguna de nacionalidad, lugar de residencia, sexo, origen nacional o étnico, color, religión, lengua, o cualquier otra condición.

La denominación "humanos" radica en que le pertenecen a la persona humana, los cuales reclaman reconocimiento, respeto, tutela y promoción de parte de todos, y especialmente de la autoridad. Sobre todo, teniendo en cuenta que se consideran derechos inherentes, indivisibles, inalienables e imprescriptibles, los cuales no están bajo la directriz del poder político, sino que están dirigidos exclusivamente por el hombre.

La situación del desplazamiento forzado está íntimamente ligada con el concepto de Derechos Humanos, en la medida en que las personas que padecen este fenómeno han sido menoscabadas en el ejercicio de sus derechos humanos a la vida digna, la libertad, la propiedad, etc. Constituye esta problemática nacional un reflejo de la flagrante violación de los Derechos Humanos como consecuencia del enfrentamiento armado producido por los grupos armados al margen de la ley presentes en el territorio colombiano.

Todos los Estados del mundo tienen el deber, independientemente de sus sistemas políticos, económicos y culturales, de promover y proteger todos los derechos humanos y las libertades fundamentales. Este principio de aplicabilidad constituye para el Estado colombiano la obligación de proteger y asistir a las personas que padecen el flagelo de desplazamiento forzado, adoptando medidas que permitan el cese de las violaciones a los derechos humanos de estas personas, así como garantizarles el ejercicio pleno de la vida en condiciones dignas.

\section{Conclusiones}

La sociedad colombiana, ante un problema tan serio, está en mora de enunciar una verdadera estrategia para responder de raíz a este drama. Aunque se han empezado a plantear soluciones desde sectores oficiales y no oficiales, se constata que en contraste con el acelerado crecimiento del problema, la definición de respuestas y programas avanza a un ritmo muy lento. Es indudable que un tratamiento exhaustivo ante la situación de desplazamiento debe ocuparse de sus causas, ${ }^{53}$ así como de la protección y las soluciones

53. Del desplazamiento Cali- Valle del Cauca: empobrecimiento del campo (29,1\%); violencia del país (70\%); en la que los más afectados son los niños, niñas y las mujeres jefes de hogar (49\%). En esta para su regreso. Estas personas como ciudadanos y ciudadanas de un país, exigen por encima de todo que las autoridades respeten y apliquen sus derechos de ciudadanos, incluido el derecho a la libertad de circulación y residencia. Se debe trabajar para evitar que esta población no se siga viendo obligada a enfrentar el drama de la exclusión, la estigmatización y el desarraigo, por lo tanto, hay que hacer partícipes a la comunidad en general, o al colectivo, en la búsqueda de una pronta solución, así como brindar una mejor y óptima calidad de vida, tal como se la merecen.

El mundo habla de una globalización y de un mercado común que invita a las diferentes naciones, grandes o pequeñas económicamente, a arriesgar con destino en las leyes del mercado. El fantasma de ideologías impuestas por las potencias en los países tercermundistas, allegaron propuestas como la del neoliberalismo económico mal aplicado por muchos, ${ }^{54}$ que se convirtió en un foco de atraso y de profundización de una crisis social a los países que tuvieron que implementarlo. El hecho de apostarle a las exportaciones, de favorecer la industria nacional, de generar competencias iguales, se aplicó en un país como Colombia lleno de corrupción, de vicios clientelistas, de cacicazgos políticos y, peor aún, en medio de un violento enfrentamiento entre una guerrilla consolidada militar y económicamente, y un débil Estado que atónito presencia el fortalecimiento de grupos paramilitares de autodefensa ${ }^{55}$ como un actor más del conflicto bélico. Las políticas globalizadoras se vendieron como la panacea a las crisis de las economías emergentes, de modo que el pueblo creyó efectivamente que hasta los problemas sociales se iban a solucionar. Sin embargo, la realidad hoy es otra, pues los neoliberalistas colombianos aplicaron la propuesta aperturista e internacionalizadora a su acomodo, favoreciendo sus propios intereses económicos y no los generales;

\footnotetext{
medida, el desplazamiento como fenómeno social es sumamente complejo y, por lo tanto, su explicación se hace muy difícil. Esto obliga a que las diferentes entidades del Estado, junto con las ONG, los organismos internacionales y la sociedad civil, unan y coordinen esfuerzos para la promoción, protección y defensa de los derechos humanos y, de manera especial, entren a investigar y dar cuenta del mismo, con el fin de definir las políticas correspondientes que lleven a la búsqueda de la paz y al logro de una convivencia civilizada. Véase Judith Chazatar y Alberto Rodríguez. IMAgINARIos COLECtivos de la Violencia de los habitantes del Municipio de Pasto. Tesis de Maestría, Centro de Estudios Avanzados en Niñez y Juventud alianza de la Universidad de Manizales y el CINDE. 54. Véase Eduardo Sarmiento. La gravedad de una apertura sin condiciones. Análisis. El Espectador.1998. 55. Véase Jaime Zuluaga Nieto. Una mirada sobre el fenómeno paramilitar. Revista Punto de Encuentro. Marzo-abril del 2005.
} 
nunca pensaron en una redistribución de excedentes, en la inversión social o en la ayuda a los desplazados.

Los indicadores, las cifras y los porcentajes ocultan dramas salvajes, niños huérfanos sin tierra y sin afectos, mujeres sumando soledades, hombres con el prestigio en la mochila y ancianos que en muchos casos han huido de varias violencias $;{ }^{56}$ comunidades enteras de indígenas que ni en las proximidades del tercer milenio pueden disfrutar la tierra que los vio nacer, y grupos étnicos negros sin rumbo. Colombia tristemente tiene en su historia varios episodios de desplazamiento: la Guerra de los Mil Días y la Masacre de las Bananeras a principios de siglo, la violencia bipartidista de mediados del siglo y la guerra de guerrillas de final de siglo. ${ }^{57}$ Los desplazados se han convertido en protagonistas históricos de la guerra y son más noticia al huir que al morir.

El tema de los desplazados debe ser una obligación de todos los implicados en soñar una sociedad más justa y equilibrada. Las personas que le apuesten al ser humano, a su pleno desarrollo, y a buscar unas condiciones que mejoren la calidad de vida de sus congéneres, deben involucrarse en él. Más cuando se proviene de una sociedad como la actual, en la que se sostiene que Colombiay el mundo necesitan personas, seres sensibles a la vida, que disfruten la música, que convivan pacíficamente con el otro y entiendan que la empresa más importante es su vida. De igual manera, este ser tiene que estar preparado para competir en el futuro profesional. La realidad quiere, o mejor exige que toda la comunidad reaccione frente a los problemas nacionales $y$, desde su propio espacio, cada uno pueda generar alternativas y soluciones para la construcción de la nueva Colombia.

La guerra transforma todo. Recibir desplazados en ciudades como Cali, Medellín, Bogotá (las cuales no se han visto afectadas por la huida de su gente, mas resienten la gran crisis social y económica por la que atraviesa el país) ${ }^{58}$ se ha vuelto un problema que ha llevado incluso a las alcaldías locales a impedir el acceso de estos ciudadanos a sus territorios, tema que desató múltiples posiciones al respecto.

\footnotetext{
56. Véase Eduardo Sarmiento. Los cuestionamientos al Dane Análisis. El Espectador. Agosto del 2005.

57. Véase Alfredo Rangel. Colombia: Guerra en el FIN DE Siglo. Universidad de los Andes, Facultad de Ciencias Sociales, тм Editores. (1998)

58. Véase Anders Kompass. Hay que desactivar la guerra. Revista Semana. Octubre del 2000.
}

\section{REFERENCIAS}

Absalón Machado. La Cuestión Agraria en Colombia A FINES DEL MILENIO. El Áncora Editores. (1998).

Acción Social. Cifras sobre el Desplazamiento en CoLOMBIA. Disponible en www.accionsocial.gov.co/SUR/ Instructivo.pdf

Adrian Onu, Thomas Pohl, Hans Krause y Silvia Bulfone Paus. Regulation of il-15 secretion via the leader peptide of two IL-15 isoforms. THE JOURNAL OF IMMUNOLOGY 158(1). 1997. Págs. 255-262.

Alfredo Molano. Los años Del tropel: Crónicas de LA Dolencia. Fondo Editorial Cerec. (1985).

Alfredo Molano. Aguas ARriba: Entre la COCA y el oro. El Áncora Editores. (1990).

Alfredo Molano. Desterrados. Crónicas del DesarraiGo. El Áncora Editores. (2001).

Alfredo Rangel. Colombia: Guerra en el fin de siglo. Universidad de los Andes, Facultad de Ciencias Sociales, TM Editores. (1998).

Anders Kompass. Hay que desactivar la guerra. Revista SEMANA. Octubre del 2000.

César Rodríguez Garavito. ¿Colombia Racista? 21 de mayo del 2008. elespeCtador.com. Disponible en http:// www.elespectador.com/impreso/tema-del-dia/articuloimpreso-colombia-racista

codhes. Un País que Huye. Desplazamiento y violenCIA EN UNA REGIÓN FRAGMENTADA. (1997).

CODHES. Mujer desplazada: violencia y discriminación. UN País que Huye. Desplazamiento y violencia en UNA REGIÓN FRAGMENTADA. CODHES. (1997).

CODHES. INICIATIVA REgIONAL ANDINA, FRONTERAS Y CONFLiCTO ARMADO INTERNO EN COLOMBIA. CODHES. (2001).

CODHES. CARACTERIZACIÓN SOCIOECONÓMICA Y POLÍTICA DE LAS ZONAS DE FRONTERA DE COLOMBIA. CODHES. (2002).

codhes. Boletín de la Consultoría de los Derechos Humanos. 60. (Julio 19 del 2005).

Conflicto, s. D. R. Informe Estructural Situación DE Riesgo por Conflicto Armado en la Costa PaCífica Caucana Municipios de Guapi, Timbiquí Y LÓPEZ DE MicAY. (2014). Disponible en wikileaks.org/ leak /bolivariana/vecka52/semanal.../semana44

Consejería de Proyectos. Asilo y Refugiados en LAS FRoNTERAS DE COLOMbia. (2003).

Consuelo Ahumada. El DESPLAZAMIENTO FORZADO DE COLOMbianos hacia Venezuela en el CONTEXTO DE 
LAS PRIORIDADES DE ESTADOS UNIDOS EN LA REGIÓN ANDINA (2000-2004). (2005).

Consuelo Ahumada et al. El desplazamiento forzado de Colombia hacia la región andina y su impacto sobre la situación política regional. COMUNIDAD ANDINA Y MERCoSUR EN LA PERSPeCTIVA DEL ALCA. Centro Editorial Javeriano-CEJA. (2003).

Consuelo Ahumada y Álvaro Moreno Duran. Prioridades del nuevo orden mundial y desplazamientoforzado de colombianos hacia Ecuador (II). LA Insignia. Diciembre del 2005. Disponible en http://www.lainsignia.org/ 2005/diciembre/ibe_030.htm

Darío Montaña Fajardo. Desterrados, entre el silencio y la esperanza. Desplazamiento forzado: Bio-política de la invisibilidad. Teología Xaveriana 149. Marzo del 2004.

Defensoría Delegada para Indígenas y Minorías Étnicas. INFORME, JULIO DE 2001. Disponible enwww.disaster-info.net/.../informes/.../jul2001/default.htm

Diana Carolina Cáceres Matías, Vilma Fabiola Izquierdo, Leonardo Mantilla, Marta Patricia Velandia, Angela González Puche y Jorge Jara Consuegra. Perfil Epidemiológico de la población Desplaza en Barrio Mandela. Ministerio de Salud, Instituto Nacional de Salud. (2001). Disponible en http://www.disaster-info.net/desplazados/ informes/mandela/informemandela.pdf

DNP. El Salto Social. Plan Nacional de Desarrollo. En Fabio Sánchez. LA Distribución DEL INGRESO EN COLOMBIA: TENDENCIAS RECIENTES Y RETOS DE LA POLÍTICA PÚBLICA. TM Editores. (1998). Págs. 174-177.

Eduardo Sarmiento. La gravedad de una apertura sin condiciones. Análisis. El Espectador. 1998.

Eduardo Sarmiento. Los cuestionamientos al Dane. Análisis. El Espectador. Agosto del 2005

Ernesto Restrepo Tirado. Desplazamiento forzado y reconstitución cultural. Éxodo, patrimonio e identidad. 5 CÁTEDRA DE HISTORIA MUSEO NACIONAL. (2000).

Estatutos de la Sociedad Nacional de la Cruz Roja Colombiana aprobados por la CONVENCión NaCIONAL EXTRAORDINARIA-Estatutaria. (Febrero de 1996).

Fedesarrollo. La ley de víctimas una reparación pendiente. Economía y Política 6o. Abril 2010. Págs. 1-6.

Fernán González S. Tradición y Modernidad en la Política Colombiana. Violencia en la Región AndinA. CINEP, APEP. (1994).

Fernando Urrea y Camilo Domínguez. (Edit.). DesplazADOS, MIGRACIONES INTERNAS Y REESTRUCTURACIONES TERritoriales. Observatorio Socio Político y Cultural. Centro de Estudios Sociales. Facultad de Ciencias
Humanas Universidad Nacional de Colombia. (1999). Germán Castro Caicedo. Sin Tregua. Editorial Planeta. (2003).

Gloria Naranjo. El derecho a la ciudad. Migrantes y desplazados en las ciudades colombianas. Desplazamiento FORZADO Y RECONFIGURACIONES URBANAS. EL CASO de Medellín y del ÁREa metropolitana 19922002. Instituto de Estudios Políticos, Universidad de Antioquia. (2002).

Gonzalo Sánchez Gómez. Guerra y POLÍ́tica eN LA SOCIEDAD COlOMBIANA. El Áncora Editores. (1991).

International Crisis Group. Colombia y sus veCinOS: LOS TENTÁCULOS DE LA INESTABILIDAD. International Crisis Group. (2003).

Jaime Zuluaga Nieto. Guerra prolongada, negociación incierta: Colombia. Comp. León Roberto Briceño. Dolencia, soCIEDAd y JUSTICIA EN AmÉrica LATiNa. Clacso. (2002).

Jaime Zuluaga Nieto. Una mirada sobre el fenómeno paramilitar. Revista Punto de Encuentro. Marzo-abril del 2005

Juan Lozano Ramírez. Luís Carlos Galán. Revista CREDENCIAL Historia 37. Enero de 1993. Disponible en http://108.168.234.58/blaa/?q=blaavirtual/revistas/credencial/enero1993/enero5.htm

Juan Manuel Bustillo. La organización de la población desplazada y la reconstrucción del tejido social. DesPLAZAMIENTO FORZADO INTERNO EN COLOMBIA: CONFLICTO, PAZ Y DESARROLLO. ACNUR-Coneys. (2001).

Judith Chazatar y Alberto Rodríguez. Imaginarios COLECTIVOS DE LA VIOLENCIA DE LOS HABITANTES DEL Municipio de Pasto. Tesis de Maestría, Centro de Estudios Avanzados en Niñez y Juventud alianza de la Universidad de Manizales y el CINDE.

Katherine Córdoba y Marcela Vela Quiroz. LA PARTICIPACIÓN POLÍTICA DE EXCOMBATIENTES DE LAS FARC-EP EN EL PROCESO DE JUSTICIA TRANSICIONAL EN COLOMBIA. (2017). Disponible en cmap.upb.edu.co/servlet/SBReadResourceServlet

Los Convenios de Ginebra del 12 de Agosto de 1949. CICR. (2012).

Manuel Atienza. Derecho y ARgumentación. Universidad Externado de Colombia. (1997).

Marcela Salazar, Andrea Duque, Yulieth Monsalve. Conflicto, violencia y convivencia social como área emergente para el trabajo social. Eleuthera, 2007, p. 130-141.

Mauricio Romero. La política en la paz y violencia. ANÁLISIS Político 45. Abril de 2002.

OACNUdH. ACV-R, CODFES. Comp. Compilación sobre DESPLAZAMIENTO FORZADO. NORMAS DOCTRINAS Y 
JURISPRUDENCIA NACIONAL E INTERNACIONAL. (Diciembre de 2001).

Olga Behar. Noches De HUMO: Cómo SE PLANEÓ Y eJeCUTÓ la toma del Palacio de Justicia. Planeta. (1988).

Orlando Gutiérrez. Estructura DE LA PROPIEDAD RURAL Y SISTEMA DE TENENCIA DE SIERRA EN SANTANDER. Funprocep, ALOP. (1990).

PARA SEMBRAR PAZ HAY QUE AFLORAR LA TIERRA. Instituto de Estudios Ambientales, IDEA, Universidad Nacional de Colombia. (1978).

PNUD. La convivencia y la paz: condiciones para la inclusión Hacia un Valle del Cauca incluyente y pacífico. Informe Regional de Desarrollo Humano IDH-VALLE 2001. PNUD. (2008).

Presidencia de la República. Una Nueva Política POR La VIDA. (Septiembre 9 de 1994).

Presidencia de la República de Colombia. Los DEsplazados, esa Colombia QUe no PODEmos ignorar. (Abril de 1998).
¿Responde realmente la cooperación internacional a lo que Colombia necesita? Desplazamiento ForZado iNTERNO EN COLOMBIA: CONFLICTO PAZ Y DESARROLLO. MEMORIAS SEMINARIO INTERNACIONAL, ACNUR-CODHES. (Junio del 2000).

Ricardo Vargas. Comp. Drogas, PODER Y REgión EN CoLOMBIA, IMPACTOS LOCALES Y CONFLICTOS. Volumen 2. CINEP. (1994).

Ricardo Vargas. Drogas, seguridad y democracia en América Latina. Jairo Estrada Álvarez Comp. El Plan ColomBIA Y LA INTENSIFICACIÓN DE LA GUERRA. Bogotá: Universidad Nacional de Colombia. (2002).

Richard Perruchoud. Derechos y Deberes internacioNALES DE LAS SOCIEDADES NACIONALES Y DE LA MEdia Luna Roja. Instituto Henry Dunant. (1982).

Sheila Gruner. Desplazamiento forzoso, políticas externas y comunidad internacional. Destierro y DESARRAIgos, Memorias del H Seminario Internacional, DesplaZAMIENTo: Implicaciones y RETOS PARA LA GOBERNABILIDAD, LA DEMOCRACIA Y LOS DERECHOS HUMANOS. Bogotá: CODHES, oI M. (Septiembre de 2002). 